\title{
Dielectric Properties of Paper Made from Pulps Loaded with Ferroelectric Particles
}

\author{
Hind El Omari, ${ }^{1,2}$ Adel Zyane, ${ }^{1,2}$ Ahmed Belfkira, ${ }^{1}$ \\ Moha Taourirte, ${ }^{1}$ and François Brouillette ${ }^{2}$ \\ ${ }^{1}$ Macromolecular and Bioorganic Chemistry Laboratory, Faculty of Science and Technology, Cadi Ayyad University, \\ Abdelkrim El Khattabi Avenue, P.O. Box 549, 40000 Marrakesh, Morocco \\ ${ }^{2}$ Lignocellulosic Materials Research Center, Québec University at Trois-Rivières, 3351 Forges Boulevard P.C. 500, \\ Trois-Rivières, QC, Canada G9A 5 H7
}

Correspondence should be addressed to Ahmed Belfkira; a.belfkira@uca.ma

Received 5 January 2016; Revised 2 March 2016; Accepted 11 April 2016

Academic Editor: Victor M. Castaño

Copyright (C) 2016 Hind El Omari et al. This is an open access article distributed under the Creative Commons Attribution License, which permits unrestricted use, distribution, and reproduction in any medium, provided the original work is properly cited.

\begin{abstract}
Due to its physical properties and its ease of manufacture, paper is widely used in various engineering applications such as electrical insulation materials for components in high voltage technology. In this study, paper loaded with ferroelectric nanoparticles $\left(\mathrm{BaTiO}_{3}\right.$ and $\mathrm{SrTiO}_{3}$ ) was made with fibers obtained from plants growing on the Moroccan soil [Halfa (Stipa tenacissima), Agave (Agave americana), Pennisetum (Pennisetum alopecuroides), Typha (Typha latifolia), and Junc (Juncus effusus)] and two commercial pulps (bleached softwood Kraft and newsprint grade thermomechanical pulps). A retention aid, cation polyacrylamide (Percol 292), was necessary to retain ferroelectric particles in the fibrous network and improve the dispersion of strontium titanate particles. The different pulp and handsheets used were characterized according to standard methods (Pulp and Paper Technical Association of Canada, PAPTAC). It is well known that annual and perennial plants contain high percentages of fines (length $<0.2 \mathrm{~mm}$ ) and short fibers. The results show that there is a strong interdependence between the dielectric properties of the loaded paper and surface finish, porosity, dispersion level of ceramic particles, fines content, shape, conformability, and sheet formation. The single dielectric relaxation detected towards low frequencies is attributed to hydroxyl groups present on fiber surfaces, in ceramic particles and adsorbed water.
\end{abstract}

\section{Introduction}

The adoption of new legislations on environmental issues is limiting the widespread use of synthetic composites. As a result, researchers have been asked to develop biodegradable and renewable products. Thus, several materials based on natural products have emerged. Raw or modified lignocellulosic fibers are some of the most interesting materials because of their highly renewable character and high annual production (50 to 100 billion tons/year) [1]. The largest natural fiber consumer is by far the paper industry. Currently, in developing countries, about $60 \%$ of cellulose fibers arise from nonwood plants: bagasse, straw, alfa, flax, sisal, and so forth $[2,3]$. The mechanical and electrical properties, surface finish, and porosity of paper made with these fibers depend on fiber extraction process, bleaching, cellulose content, fiber length and conformability, fiber source, presence of metal ions, moisture content, and manufacturing process [4-8].

More commonly used as a writing support and in packaging, paper has also been used in the electrical field as an insulator in power transformers and high voltage applications. Within a highly porous fibrous structure, the intimate surface of contact between the capacitor plates and the paper is very low; therefore, it is often used in the form of cardboard impregnated with mineral oil [1]. Indeed, paper has a low dielectric constant (between 1 and 2.5) with respect to pure cellulose (6 to 8.1) [7]. Thus, several lignocellulosic fibers/polymer matrices combinations were explored to find a composite with interesting properties. The objectives were to observe synergy between the properties of the matrix and fillers to simultaneously improve the strength of the material, electrical and sound insulation, and dielectric properties [9]. The dielectric properties of the paper can also 
be improved by the addition of suitable fibers. The addition of synthetic fibers (polyacrylic) decreased the tangent angle of dielectric loss and improved mechanical properties. This type of paper was used as electrical insulation for cables [1012]. This does not always happen. Indeed, the introduction of $\mathrm{TiO}_{2}$ nanoparticles in the oil-impregnated paper reduces its constant and dielectric loss [13]. The dielectric properties of such materials change over time (decrease of the life cycle) as a result of cellulose chains depolymerization promoted by the presence of oxygen, moisture, and temperature variations [14-16].

A series of studies determined the electrical properties of paper made from agricultural residue pulps and their linseed oil-impregnated counterparts (e.g., rice straw paper, cotton stalks paper, and bagasse paper) [17-20]. These materials have shown interesting dielectric properties. This motivated more studies on the electrical properties of paper made from low cost and abundant plant materials [5].

In this study, the properties of paper made from plants fiber and commercial pulps were evaluated. The effect of the composition of the pulp and the introduction of ferroelectric particles in the presence of a retention aid on the mechanical and electrical properties was also discussed. The aim of this study is to show the potential of perennial plants as an electrical insulation material. These fibers show good insulating properties in addition to several advantages such as abundance, biodegradability, and ease of manufacture at low cost.

\section{Experimental}

\subsection{Raw Materials}

2.1.1. Lignocellulosic Fibers. Seven (7) different lignocellulosic pulps were used in this study. Five were extracted from plants growing on Moroccan soil [Halfa (Stipa tenacissima), Agave (Agave americana), Pennisetum (Pennisetum alopecuroides), Typha (Typha latifolia), and Junc (Juncus effusus)]. The two other samples were industrial pulps: bleached softwood Kraft and thermomechanical pulps (TMP) provided, respectively, by Kruger Inc.-Wayagamack and Kruger Inc.-Trois-Rivières mills (Canada). The plants were collected in the area of Kelaa Sraghna on the edge of the Lakhdar River. Pulps have undergone the same treatment. They were treated with sodium hydroxide $(\mathrm{NaOH}, 2 \%)$ and hydrogen peroxide $\left(\mathrm{H}_{2} \mathrm{O}_{2}, 2 \%\right)$ at a temperature of $80^{\circ} \mathrm{C}$ for $8 \mathrm{~h}$. This allowed the removal of hemicelluloses and lignin. After washing with distilled water to neutral $\mathrm{pH}$, the fibers were dried in an oven at $60^{\circ} \mathrm{C}$. The composition of each pulp, fines percentage, and length weighted average fiber length were determined by the FQA (Fiber Quality Analysis).

2.1.2. Ceramics. Two types of ceramics were used: barium titanate $\left(\mathrm{BaTiO}_{3}, d=6.08\right)$ and strontium titanate $\left(\mathrm{SrTiO}_{3}\right.$, $d=4.81)$. Both particles had a nanometric size $(<100 \mathrm{~nm})$. They were supplied by Sigma-Aldrich.

2.1.3. Retention Agent. Ceramics loss during paper formation was prevented by a retention aid. A cationic polyacrylamide
(CPAM), Percol 292, supplied by Ciba Specialty Chemicals, was used.

2.2. Production of Loaded Paper. The handsheets, with and without (as a reference) ceramic, were prepared according to a standard papermaking method (TAPPI T205 sp-954). Upon preparing handsheets with plant pulps, a weight loss around 30\% occurred. A similar phenomenon was observed upon the preparation of paper loaded with ceramic particles, despite the use of the retention agent. Also, an optimization study aiming at improving preparation conditions has been performed. Indeed, for the preparation of handsheets with a mass of around $1.2 \mathrm{~g}$, we used $1.51 \mathrm{~g}$ of pulp. For loaded sheets, a mass of fibers containing $0.1 \mathrm{mg} / \mathrm{g}$ of retention agent was first stirred during 5 minutes and thereafter a certain quantity of ceramic was added in order to reach weight compositions equivalent to $10,20,30$, and $40 \%$. After 15 minutes of stirring, a wet sheet was obtained on the handsheet machine.

2.3. Handsheets Characterization. Mechanical tests, porosity, and roughness were measured in controlled temperature and humidity environment according to the PAPTAC standard methods: PAPTAC D 31 (porosity), PAPTAC D 31 (roughness), and PAPTAC D 34 (tensile tests). Ceramic loadings were determined from the ash contents of the sheets. Scanning electron microscopy (SEM) images of the sheet structure were taken using a JSM-5500 system (JEOL Ltd.).

The crystallinity of each sample was determined by X-ray diffraction using a Bruker AXS D8 Advance diffractometer with a scintillation detector and a cobalt tube, with the PANalytical X'Pert HighScore software. The crystallinity index of various cellulose fibers was evaluated according to the Segal method using the following equation [21]:

$$
\operatorname{Crystallinity}(\%)=\left[\frac{I_{002}-I_{\mathrm{am}}}{I_{002}}\right] \times 100,
$$

where $I_{002}$ is the diffraction intensity of the (002) plane at $2 \theta$ angle between $22^{\circ}$ and $23^{\circ}$ and $I_{\mathrm{am}}$ is the diffraction intensity of the amorphous part, which is taken at $2 \theta$ angle between $18^{\circ}$ and $19^{\circ}$ where the intensity is minimal.

The dielectric measurements were carried out at room temperature with an impedance meter (Agilent 4294A) using a cell (Agilent 16451B) allowing the direct measurement, without sample metallization. The swept frequency range was between $100 \mathrm{~Hz}$ and $1 \mathrm{MHz}$ [22]. The samples were dried in an oven at $105^{\circ} \mathrm{C}$ to remove the residual water. The dielectric constant is calculated by

$$
\varepsilon=\frac{t_{\alpha} \times C_{p}}{A \times \varepsilon_{0}},
$$

where $t_{\alpha}$ is the average thickness of sample $(\mathrm{m}), A$ is guarded electrode's surface area $\left(\mathrm{m}^{2}\right), \varepsilon_{0}$ stands for the permittivity of free space $\left(8.854 \times 10^{-12} \mathrm{~F} / \mathrm{m}\right)$, and $C_{p}$ corresponds to the equivalent parallel capacitance of sample (F) [22].

\section{Results and Discussion}

3.1. Pulp Characterization. Fines content as well as length weighted average fiber length (LW) of various plants was close 
TABle 1: Pulp and handsheet characteristics.

\begin{tabular}{lccccccc}
\hline Fibers & $\begin{array}{c}\text { Handsheet } \\
\text { weight }(\mathrm{g})\end{array}$ & $\begin{array}{c}\text { Fines content } \\
(\%)\end{array}$ & $\begin{array}{c}\text { Average fiber } \\
\text { length }(\mathrm{mm})\end{array}$ & $\begin{array}{c}\text { Porosity } \\
(\mathrm{mL} / \mathrm{min})\end{array}$ & Roughness $(\mu \mathrm{m})$ & $\begin{array}{c}\text { Crystallinity } \\
\text { rate }(\%)\end{array}$ & $\begin{array}{c}\text { Young modulus } \\
(\mathrm{MPa})\end{array}$ \\
\hline Agave & 1.23 & 46.55 & 0.52 & 7637 & 10.93 & 44.05 & 715.50 \\
Typha & 1.17 & 36.21 & 0.37 & 2146 & 8.67 & 63.85 & 1536.70 \\
Pennisetum & 1.22 & 39.74 & 0.44 & 12310 & 8.52 & 64.77 & 1089.13 \\
Junc & 1.21 & 36.17 & 0.35 & 12900 & 10.31 & 72.73 & 754.92 \\
Halfa & 1.18 & 36.62 & 1.15 & 47918 & 12.39 & 74.73 & 339.02 \\
Kraft & 1.23 & 25.73 & 1.21 & 11339 & 8.17 & 69.27 & 1312.13 \\
TMP & 1.18 & 37.50 & 0.77 & 5765 & 9.19 & 59.04 & 1194.45 \\
\hline
\end{tabular}

to the values found by other authors who studied annual and perennial plants (Table 1) [23-25]. Generally, plant pulps have much smaller fibers compared to tree pulps because of their high fines content (small particles with a length lower than $0.2 \mathrm{~mm}$ ). For papermaking materials, particles that pass through a $75 \mu \mathrm{m}$ diameter round hole or a 200 -mesh screen (the P200 fraction of a Bauer-McNett classifier) are generally considered as fines. In general, the amount of fines depends on fiber source, fiber morphology, pulping conditions, and the magnitude of mechanical treatment [26]. The presence of fines presented effects on mechanical, electrical, and surface properties of the sheet. In fact, it seemed that fines plasticized the sheet and reduced its tensile strength (from a certain content) and improved the flexibility. Likewise, the presence of fines enhanced dielectric permittivity, owing to their high surface energy, by promoting the formation of dipoles as further described below. Otherwise, the presence of fines improved the flatness and therefore the contact between the material and the electrodes.

3.2. Unloaded Handsheets Characterization. The results of analyses carried out on handsheets are summarized in Table 1. The properties differ from one plant to another. As the modes of extraction and bleaching are the same, we can relate these variations mainly to fiber length and conformability, fines percentage, presence of kinks and curves, surface quality, formability, and formation mode $[27,28]$. Therefore, the measured values consist in the combination of these different parameters. The presence, for example, of high fines content will fill voids between fibers and will play the role of plasticizers in reducing Young's modulus and decreasing porosity as well as roughness by filling empty spaces [29-34].

Scanning electron microscopy (SEM) images for different handsheets (Figure 1: case of Halfa without ceramics) show a state of entanglement and empty space between fibers, confirming the high porosity in our samples.

3.3. Dielectric Properties. The most common factors that must be considered in dielectric measurements are the homogeneity of the material, the flatness of the surface, the presence of air, and the metallization or not of the sample and the dielectric losses (equipment). Our material is heterogeneous (cellulose, lignin, fines, and other impurities related to extraction processes of fibers and the origin of the plant) and hydrophilic, with rough surfaces and consequently a lack of flatness, necessary for a good contact with the electrodes.

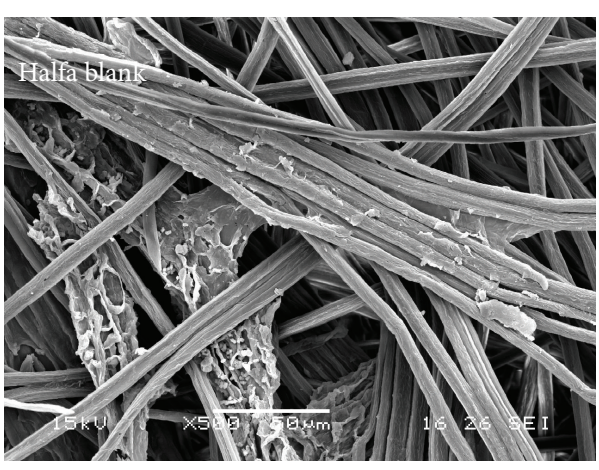

FIGURE 1: SEM image of paper from Halfa fibers.

Since the dimensional parameters are considered constant (thickness and temperature), the measurement error of the dielectric constant $\left(\varepsilon_{r}\right)$ is none other than the measurement error of the capacitance $\left(C_{p}\right)$, which is approximately $5 \%$.

3.3.1. Unloaded Handsheets. The variation of dielectric constant with frequency for our material is represented in Figure 2(a). The orientation of the polarization contribution is mainly noticeable in the low frequency region up to 1010 Hertz. Electronic and ionic polarizations always occur below 1013 Hertz. The decay of $\varepsilon^{\prime}$ values, depending on the frequency, confirms the predominance of the orientation polarization with the voltage stress (materials with high specific volume) [7].

At low frequencies, there is an orientation of permanent dipoles, located at fiber surfaces, while at medium and high frequencies the orientation becomes difficult [35]. The two main factors contributing to the loss factor $(\operatorname{tg} \delta)$ are dipole polarization and ionic conductance [36].

It is observed from Figure 2(b) that the loss factor values are high in the low frequency region and this applies to all frequencies. The reduction of the loss factor with frequency indicates that it also depends on the polarization of groups located at fiber surfaces, which is minimal at very high frequencies [37].

We found no relationship between the dielectric constant and the crystallinity. This is certainly the difficulty of dielectric measurements of this type of material (rough and porous leading to poor electrode contact) (Table 2). According to Nada et al. (2004) [38], the permittivity must increase when the crystallinity rate decreases. They 


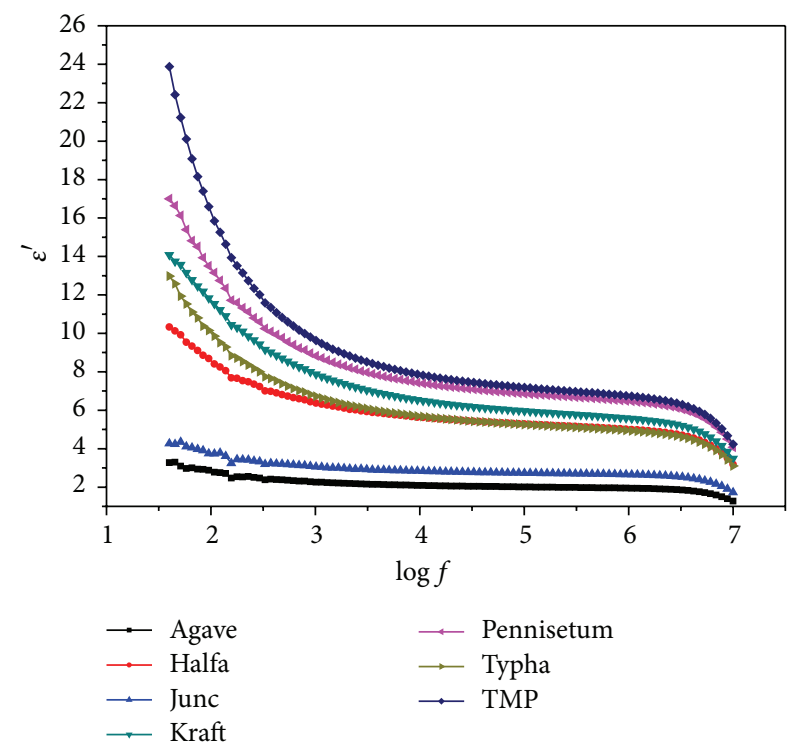

(a)

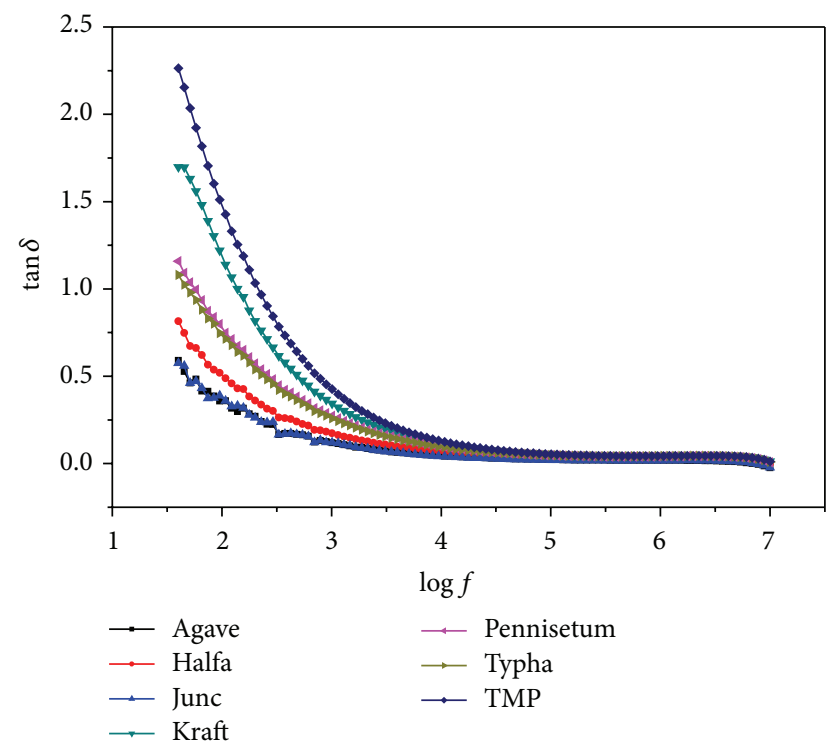

(b)

FIGURE 2: Evolution of dielectric constant (a) and loss factor (b) as a function of frequency for different handsheets from various fibers.

TABLE 2: Dielectric constant, loss tangent angle (at $f=100 \mathrm{~Hz}$ ), and crystallinity of different fibers.

\begin{tabular}{lccc}
\hline Fibers & $\varepsilon^{\prime}$ & $\varepsilon^{\prime \prime}$ & Crystallinity rate (\%) \\
\hline Agave & 2.77 & 0.99 & 44.05 \\
Halfa & 8.41 & 4.11 & 61.80 \\
Junc & 3.73 & 1.35 & 64.77 \\
Pennisetum & 13.15 & 9.83 & 72.73 \\
Typha & 9.85 & 7.04 & 74.43 \\
Kraft & 11.53 & 13.14 & 69.27 \\
TMP & 15.84 & 22.61 & 59.04 \\
\hline
\end{tabular}

attributed this behavior to a relative freedom of orientation of hydroxyl groups in $\mathrm{C}_{6}$ of the cellulose chain under the action of the electric field in amorphous zones. Crystalline zones are characterized by strong interactions: hydroxyl groups are strongly bounded and will be less ready to be oriented. In the disordered regions, molecular or dipolar polarization will also be influenced by the proximity and configuration of adjacent molecules. The decrease in crystallinity promotes disorder, molecules are less related, and therefore a higher dielectric constant was achieved [39].

We can note from Table 2 that crystallinity in our samples does not really affect the dielectric constant of paper; there is no clear relationship between the two variables. For example, Agave has the lowest rate of crystallinity and has the lowest dielectric constant. This is the opposite of what was found by Nada et al. (2004) [38]. Indeed, dielectric measurements on paper are very difficult because results depend on several parameters as indicated above (roughness, porosity, dispersion level of ceramic particles, fines content, sheet formation, etc.).
3.3.2. Loaded Handsheets. The incorporation of ferroelectric particles $\left(\mathrm{BaTiO}_{3}\right.$ and $\left.\mathrm{SrTiO}_{3}\right)$ involves a drop in the mechanical properties of handsheets as shown in Figure 3 (the case of Pennisetum fibers) and Table 3. The drops of Young's and elasticity modulus are similar. However, it is noticeable that the drop for sheets containing the strontium titanate $\left(\mathrm{SrTiO}_{3}\right)$ is much faster. This indicates that introduced particles reduced fiber-fiber interactions responsible for the cohesion of the network.

SEM images (Figure 4) show that ceramic particles are dispersed in the case of $\mathrm{SrTiO}_{3}$ whereas in the case of $\mathrm{BaTiO}_{3}$ many particles remain in the form of agglomerates on the surface of fibers. In consequence, decreasing fiber-fiber interactions will be more important in the case of strontium titanate at the expense of fiber/load interactions. Indeed, this will affect the dielectric properties. The increase in porosity with the incorporation of charges is also a confirmation that the presence of strontium titanate results in lower mechanical properties and a much larger increase of porosity (Table 4).

The dielectric constant $\left(\varepsilon^{\prime}\right)$ depends mainly on the contributions of interface, orientation, and atomic and electronic polarization in the material. A thin isotropic distribution of ceramic particles in the fiber network will result in a sort of percolation and consequently an increase in the dielectric constant. This is also confirmed by the values obtained with our samples. In fact, the results obtained with strontium titanate, whose particles are better dispersed in the fibrous network than barium titanate ones, show higher permittivities. The high values of dielectric constant at low frequencies and at room temperature are certainly the result of orientation movements of hydroxyl groups present at the component surface of our material. A decline of this magnitude at high frequencies confirms the low contribution of other polarizations. 
TABLE 3: Tensile properties of ceramic loaded handsheets.

\begin{tabular}{|c|c|c|c|c|c|c|c|c|c|c|c|c|c|c|c|c|c|c|c|c|}
\hline \multicolumn{3}{|c|}{ Agave } & \multicolumn{3}{|c|}{ Halfa } & \multicolumn{3}{|c|}{ Pennisetum } & \multicolumn{3}{|c|}{ Junc } & \multicolumn{3}{|c|}{ Typha } & \multicolumn{3}{|c|}{ Kraft } & \multicolumn{3}{|c|}{ TMP } \\
\hline$\%$ & $\mathrm{MF}$ & E & $\%$ & ME & E & $\%$ & $\mathrm{MF}$ & E & 10 & ME & E & $c_{1}$ & ME & E & 10 & ME & $E$ & $\%$ & ME & $E$ \\
\hline \multicolumn{21}{|c|}{$\mathrm{SrTiO}_{3}(\%$ : percentage, ME: modulus of elasticity (MPa), and $E$ : Young's modulus (MPa)) } \\
\hline .3 & 8.8 & ; & 3 & $=0$ & & 97 & & & 70 & & & & & & & & & 8 & 6.2 & \\
\hline 0.4 & 654.9 & 9.0 & .8 & 2 & & 21.4 & ( & & & & & & & & & & & 9 & 17.2 & \\
\hline & & & 24.7 & 4 & & & & & & & & & & & & & & 1 & 31.5 & \\
\hline & & & & 520.0 & 370.7 & 37.9 & & & & & & & & & & & & & 828.6 & \\
\hline \multicolumn{21}{|c|}{$\mathrm{BaTiO}_{3}$ (\%: percentage, ME: modulus of elasticity (MPa), and $E$ : Young's modulus (MPa)) } \\
\hline 0 & & & & & & & & & & & & & & & & & & & 195.J & \\
\hline 3.7 & 587.6 & 19.5 & 18.2 & 381. & 3 & 18.6 & & & 20 & & & & & & & & & 19.4 & 972.1 & \\
\hline 29.5 & 577.5 & 616.6 & 24.1 & 341.3 & 376. & 27.0 & 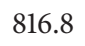 & 4 & 27.3 & 59 & 63 & 22 & & & 22.8 & & & 27.1 & 910.1 & 973.7 \\
\hline 5.4 & 73.8 & 598.6 & 1.2 & 322.2 & 60.8 & 32.1 & 94.5 & 827.1 & 37.6 & 587.9 & 628.8 & 38.1 & 1126.0 & 180.7 & 30.5 & 628.1 & 663.3 & 33.0 & 941.6 & 996. \\
\hline
\end{tabular}

TABLE 4: Ceramic rate/paper porosity.

\begin{tabular}{|c|c|c|c|c|c|c|c|c|c|c|c|c|c|}
\hline \multicolumn{2}{|c|}{ Agave } & \multicolumn{2}{|c|}{ Halfa } & \multicolumn{2}{|c|}{ Pennisetum } & \multicolumn{2}{|c|}{ Junc } & \multicolumn{2}{|c|}{ Typha } & \multicolumn{2}{|c|}{ Kraft } & \multicolumn{2}{|c|}{ TMP } \\
\hline$\%$ & $P$ & $\%$ & $P$ & $\%$ & $P$ & $\%$ & $P$ & $\%$ & $P$ & $\%$ & $P$ & $\%$ & $P$ \\
\hline \multicolumn{14}{|c|}{$\mathrm{SrTiO}_{3}\left(\%\right.$ : ceramic loading; $P$ : porosity $\left.10^{-3} \mathrm{~mL} / \mathrm{min}\right)$} \\
\hline 15.3 & 6.2 & 11.3 & 26.9 & 9.7 & 12.9 & 7.9 & 14.3 & 9.8 & 1.4 & 7.7 & 13.5 & 11.8 & 10.2 \\
\hline 20.4 & 11.4 & 19.8 & 33.6 & 21.4 & 13.15 & 21.5 & 13.13 & 21.7 & 2.1 & 17.9 & 13.3 & 19.9 & 10.2 \\
\hline 27.7 & 11.6 & 24.7 & 25.7 & 31.1 & 13.3 & 28.6 & 13.5 & 24.5 & 3.9 & 27.5 & 13.5 & 27.1 & 11.7 \\
\hline 35.7 & 11.6 & 37.3 & 26.7 & 37.9 & 13.4 & 38.4 & 15.1 & 41.0 & 4.5 & 33.2 & 14.2 & 31.4 & 11.5 \\
\hline \multicolumn{14}{|c|}{$\mathrm{BaTiO}_{3}$ (\%: ceramic loading; $P$ : porosity $\cdot 10^{-3} \mathrm{~mL} / \mathrm{min}$ ) } \\
\hline 12.6 & 8.1 & 9.2 & 36.4 & 11.5 & 13.8 & 10.2 & 12.8 & 11.8 & 1.1 & 8.5 & 13.9 & 7.5 & 7.5 \\
\hline 18.7 & 9.2 & 18.2 & 29.1 & 18.6 & 13.6 & 20.1 & 13.6 & 22.2 & 1.7 & 15.5 & 13.1 & 19.4 & 8.1 \\
\hline 29.5 & 10.0 & 24.1 & 26.3 & 27.0 & 14.2 & 27.3 & 14.3 & 22.7 & 1.9 & 22.8 & 14.0 & 27.1 & 8.4 \\
\hline 35.4 & 11.6 & 31.2 & 22.7 & 32.1 & 13.5 & 37.6 & 14.0 & 38.1 & 2.5 & 30.5 & 13.2 & 33.0 & 6.4 \\
\hline
\end{tabular}

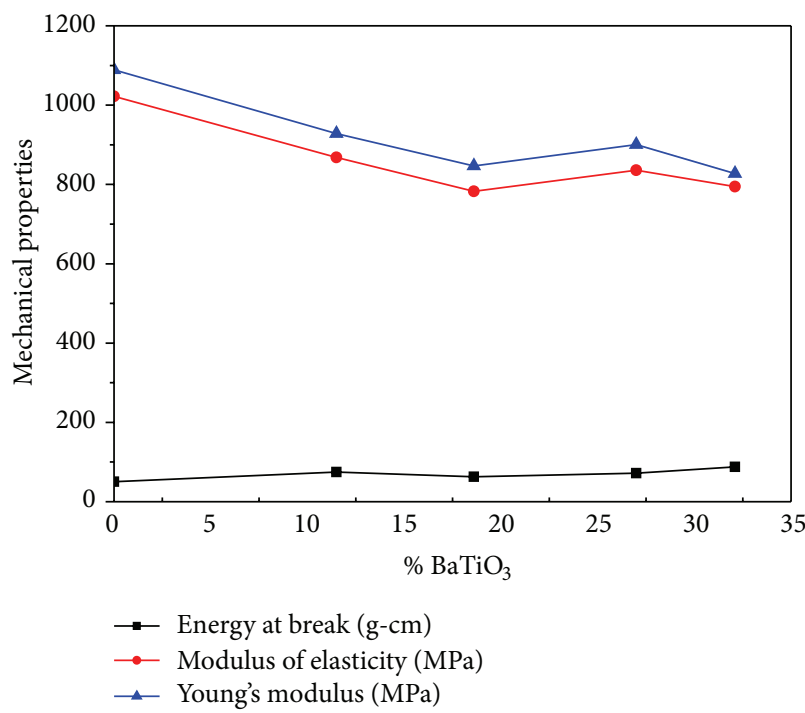

(a)

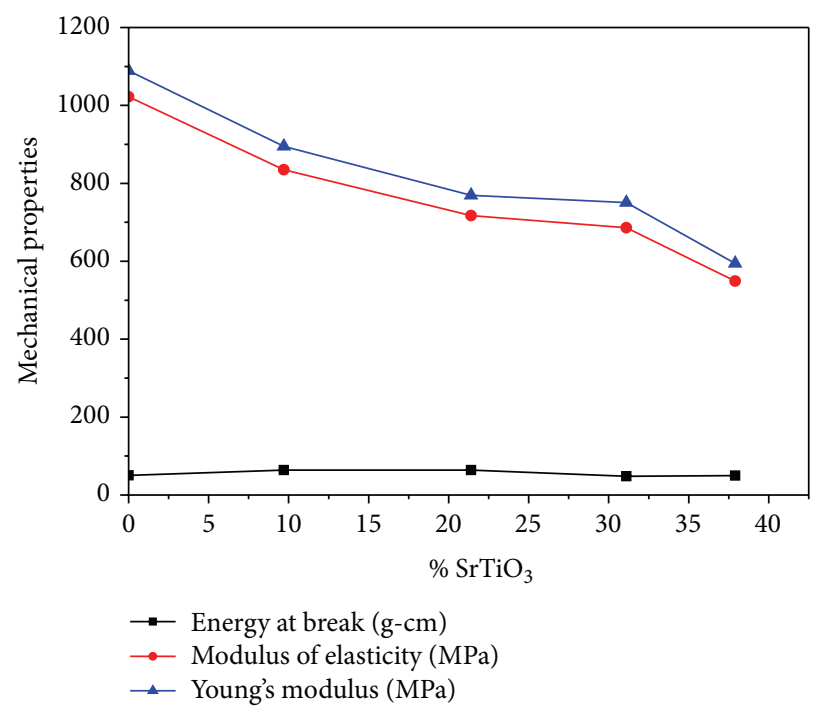

(b)

FIGURE 3: Evolution of Young's modulus, modulus of elasticity, and break energy of Pennisetum fiber when incorporating various percentages of ferroelectric particles $\mathrm{BaTiO}_{3}(\mathrm{a})$ and $\mathrm{SrTiO}_{3}(\mathrm{~b})$. 


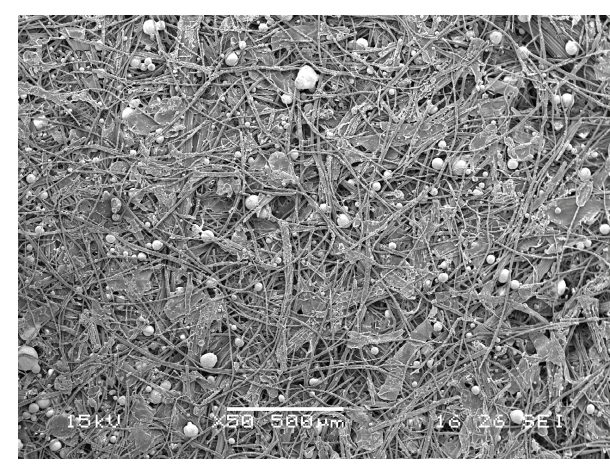

(a)

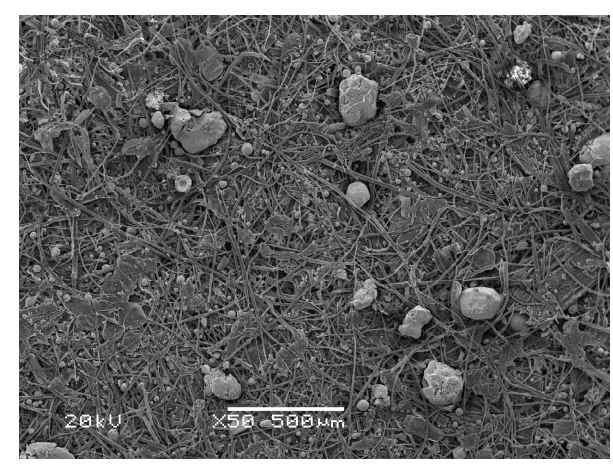

(b)

Figure 4: SEM images of Pennisetum loaded paper: (a) $37.9 \% \mathrm{SrTiO}_{3}$ and (b) $32.1 \% \mathrm{BaTiO}_{3}$.

It is not easy to explain the change in the response of our handsheets to electrical solicitation. Indeed, several factors must be taken into consideration: (i) fibers with kinks and curves will generate very uneven surfaces, (ii) porosity is not the same for all handsheets, and (iii) particles dispersion is not the same for the two ceramics. Therefore, formation of dipole chains and their intimate contact with the capacitor plates will be random. Likewise, it is not surprising that dielectric response of cellulosic materials has led to controversy in the past [8]. We obtained different responses with the two ceramics. In the case of paper loaded with $\mathrm{SrTiO}_{3}$, permittivity $\left(\varepsilon^{\prime}\right)$ increases with the rate of loading (Figure 5(a)). SEM images of paper, realized with this ceramic, show a good dispersion of particles in the fiber network (Figure 4(a)).

Improving $\varepsilon^{\prime}$ can be attributed to the creation of macrodipoles: ceramic particles/fibers $/ \mathrm{H}_{2} \mathrm{O}$ (Figure 5(c)). The presence of hydroxyl groups on the different surfaces of the two components (fiber/filler) in addition to the water adsorbed on them will create dipole chains associated by hydrogen bonds. The same result was obtained by El-Meligy et al. (2010) [40] and Popielarz and Chiang (2007) [41]. The increase in the number of fiber/particle contacts will certainly lead to an increase in the number of dipoles in the material.

Different handsheets show a significant increase depending on the load factor except for two fibers: Kraft and Junc (Figure 6). Examination of SEM pictures of these two handsheets shows the presence of agglomerates and areas containing only very few particles (Figure 6).

The significant improvement of the dielectric constant for paper loaded with $\mathrm{SrTiO}_{3}$ is attributed to the high permittivity of $\mathrm{SrTiO}_{3}$ (300) and to the good dispersibility of particles in the fibrous network (Figure 4(a)). Some $\varepsilon^{\prime}$ values in excess of 21 were recorded for several fibers (Agave, Halfa, Pennisetum, Typha, and TMP) while a typical insulating paper generally does not exceed 4 [7, 42, 43]. Good dispersion of $\mathrm{SrTiO}_{3}$ particles in fiber network and excellent interfacial adhesion between fibers and $\mathrm{SrTiO}_{3}$ nanoparticles (Figure 4(a)) are the factors that influence the dielectric properties of the material [44]. The effect of $\mathrm{BaTiO}_{3}$ ceramics is much less important than $\mathrm{SrTiO}_{3}$
(Figure 7(a)). SEM images of samples loaded with ceramic show agglomerates of particles adsorbed on fiber surfaces (Figure 4(b)). The poor dispersion of particles reduces dipole chains formation in the material between the two plates (Figure 7(c)).

The porosity of all handsheets is represented in Table 4 . It is noticed that the introduction of ceramic particles $\left(\mathrm{SrTiO}_{3}\right.$ and $\mathrm{BaTiO}_{3}$ ) results in an increase in porosity. Ceramic particles on fiber surfaces will decrease, by location, fiberfiber contact. Agglomerates of less dispersed particles, as in the case of $\mathrm{BaTiO}_{3}$, will create large empty spaces eventually preventing fiber-fiber and fiber-microparticle contacts. A good dispersion of nanoparticles in the network will promote more fiber-particle interaction. This is confirmed by the dielectric response of various handsheets. Paper with strontium titanates shows high dielectric constants. This is due to the formation of dipoles chains between the two plates of the capacitor.

Regarding the loss factors, the effect of the introduction of the two ceramics differs. For strontium titanates, as shown in Figure 8(a), there is an increase in losses, in comparison with the blank, with load concentration. This confirms what we have advanced concerning the distribution of particles and macrodipole formation. In contrast with $\mathrm{BaTiO}_{3}$, compared with handsheets without ceramics, a decrease in losses is noticed (Figure 8(b)).

\section{Conclusions}

The dielectric properties of paper from annual and commercial plants, loaded with the two most studied ferroelectric ceramics $\left(\mathrm{BaTiO}_{3}\right.$ and $\left.\mathrm{SrTiO}_{3}\right)$, were evaluated. Dispersion and retention of $\mathrm{SrTiO}_{3}$ particles with a cationic polyacrylamide (CPAM) were more effective as shown in the SEM images and the dielectric properties. Dielectric response, SEM images, dispersion of particles, and porosity results explain the improvement of the dielectric constant in the case of the strontium titanate.

The present study mainly highlights the dielectric behavior of paper developed from plants with and without filler loads. It showed that 

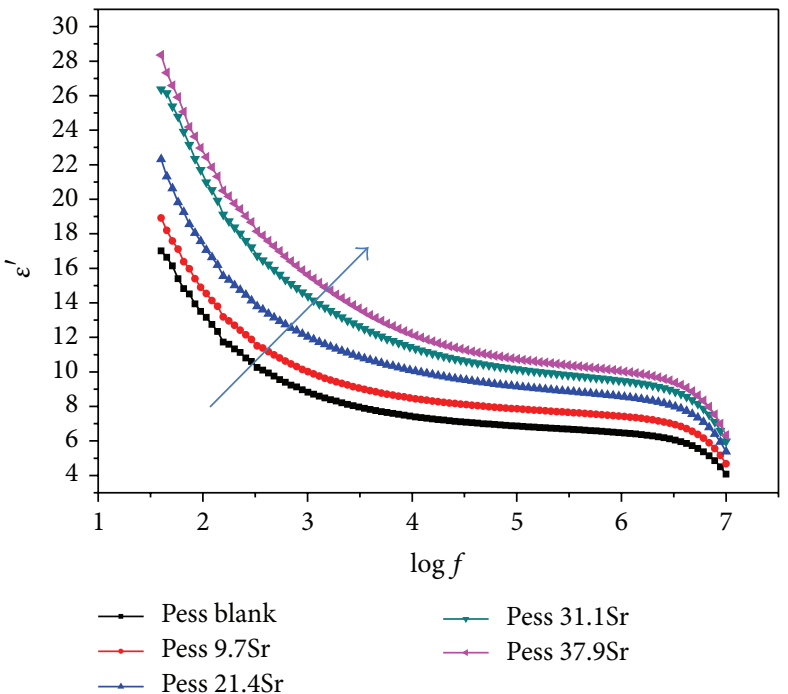

(a)

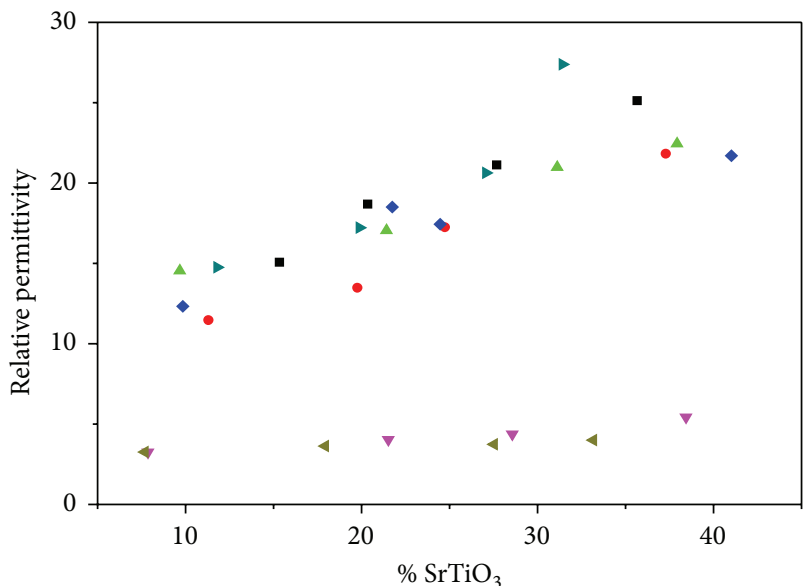

- Agave

- Halfa

- Typha

$\triangle$ Pennisetum

$\checkmark$ Junc

(b)

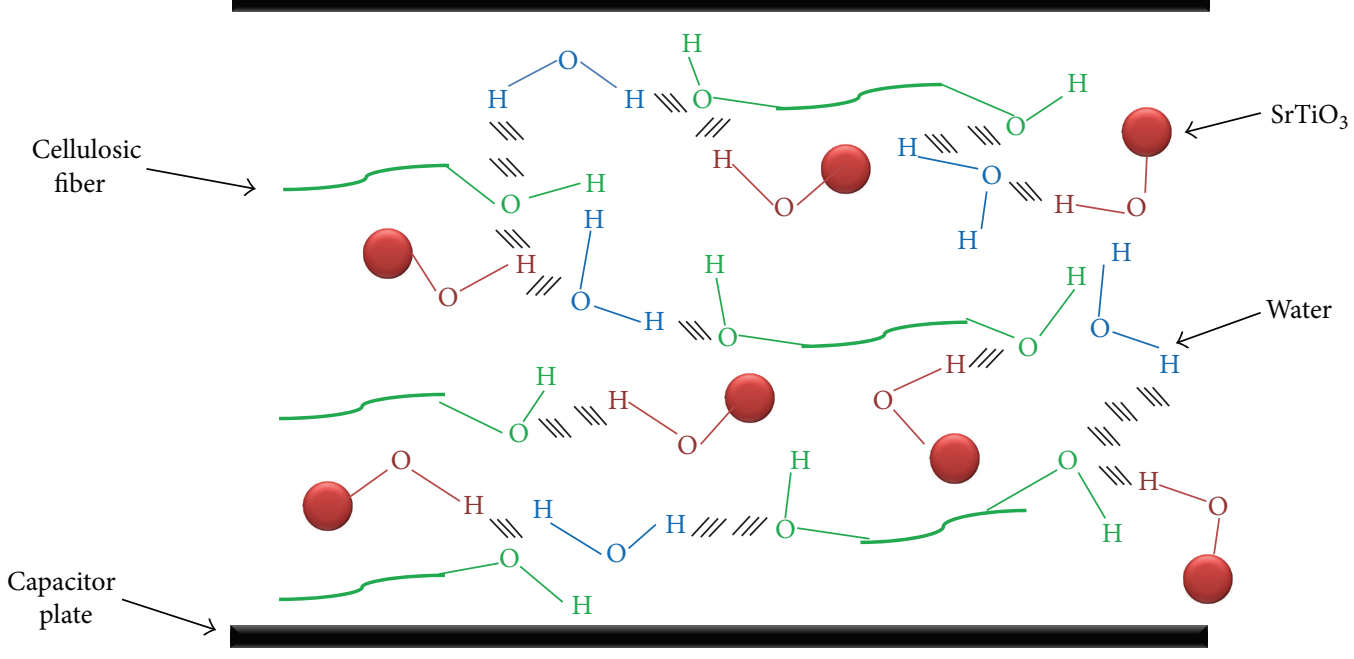

(c)

FIgURE 5: Permittivity variation with load rate of $\mathrm{SrTiO}_{3}$ as function of frequency (a) and load factor (b). Particles dispersion without agglomerates in the case of $\mathrm{SrTiO}_{3}(\mathrm{c})$.

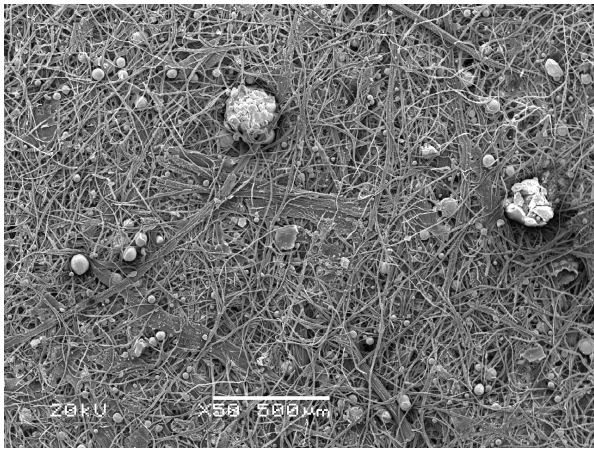

(a)

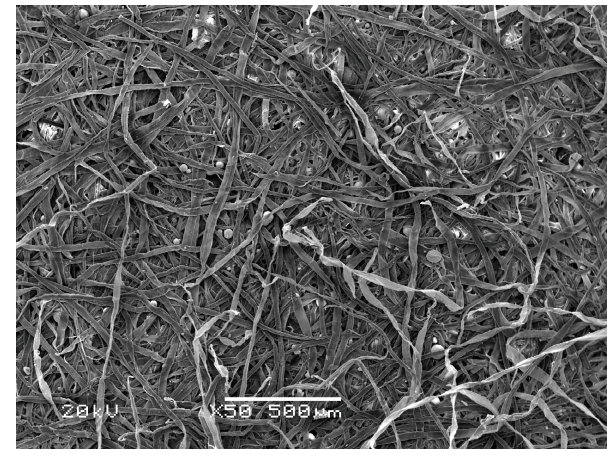

(b)

Figure 6: Poor dispersion of $\mathrm{SrTiO}_{3}$ particles in (a) Junc (38.4\%) and (b) Kraft (33.2\%). 


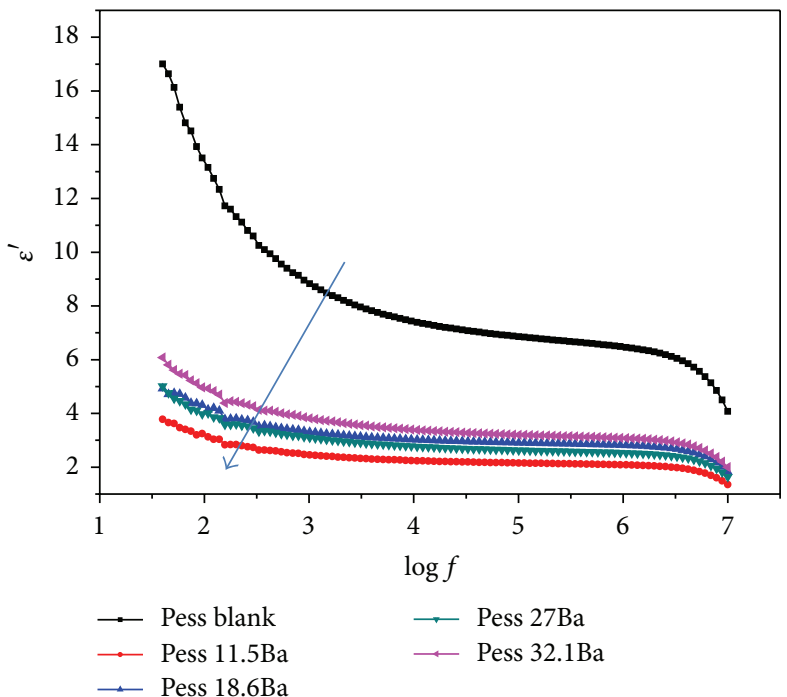

(a)

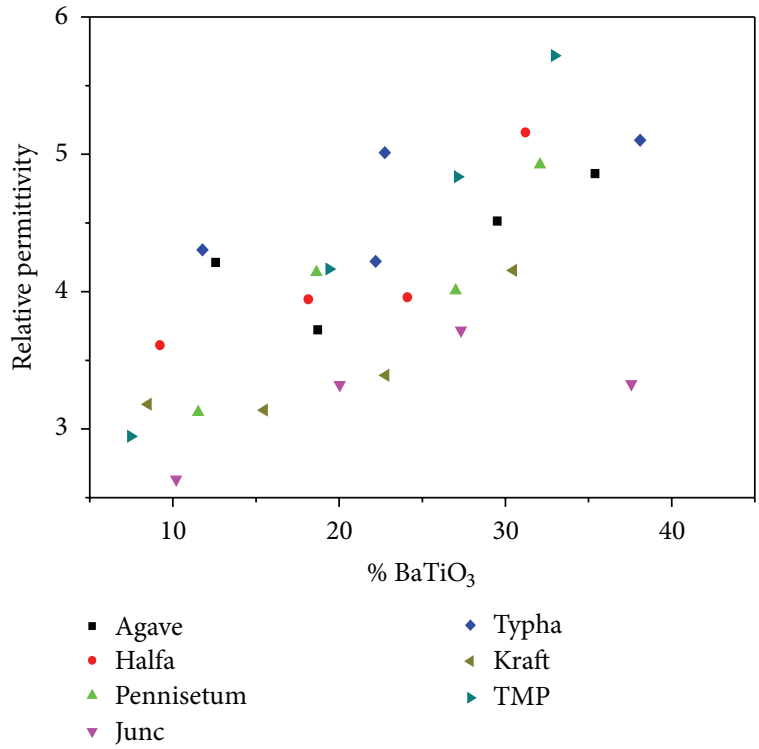

(b)

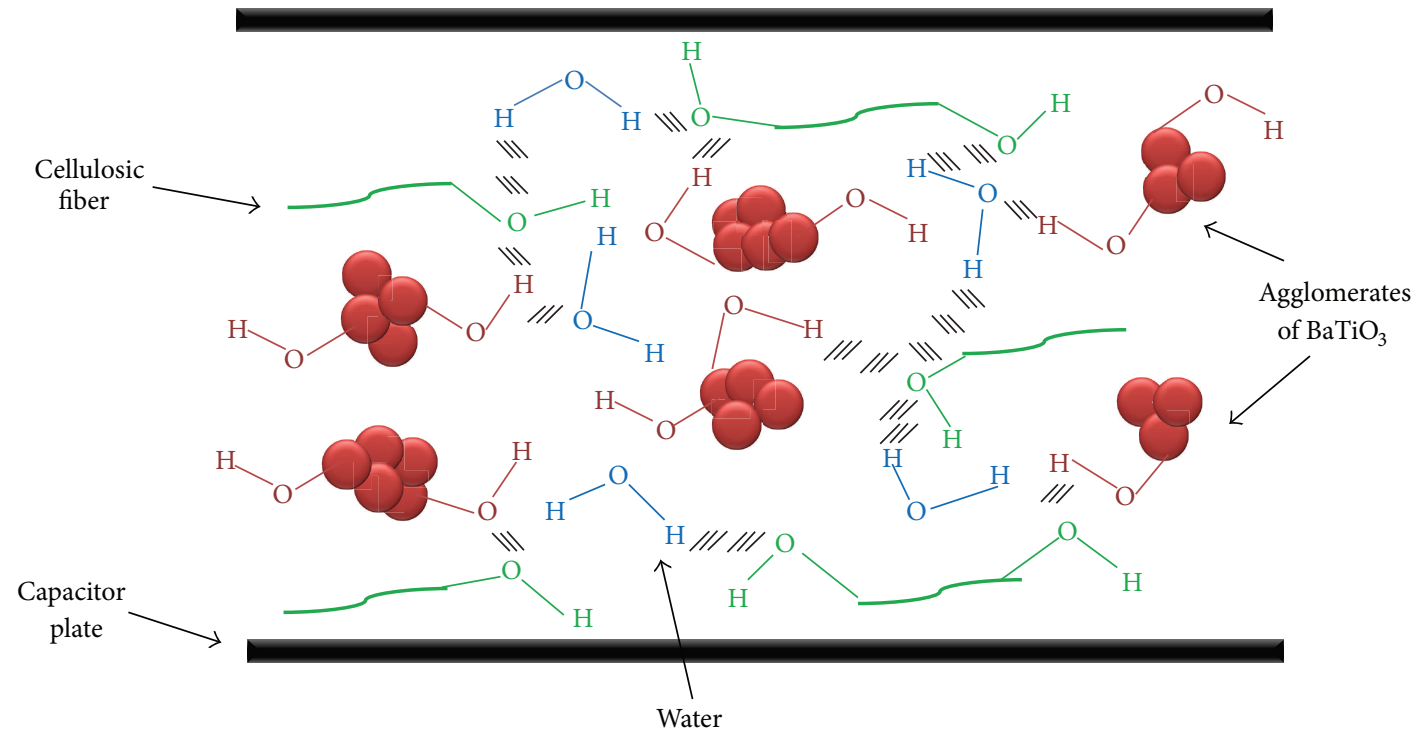

(c)

Figure 7: Effect of $\mathrm{BaTiO}_{3}$ introduction on $\varepsilon^{\prime}$ as function of frequency (a) and permittivity variation with load rate of $\mathrm{BaTiO}_{3}$ (b). Agglomerate particles preventing the formation of dipoles in the case of $\mathrm{BaTiO}_{3}(\mathrm{c})$.

(i) the dispersion and retention of the ferroelectric particles (ceramics) required a retention agent,

(ii) the presence of fines yields the improvement of the dielectric constant by the creation of dipoles and the increase of contact surface.

\section{Competing Interests}

The authors declare that they have no competing interests.

\section{Acknowledgments}

The authors would like to express their gratitude to all the members of the Laboratory of Bioorganic and Molecular Chemistry (Marrakesh, Morocco), the Lignocellulosic Materials Research Center (Trois-Rivières, Canada), and the laboratory of Science of Ceramic Processes and Treatments Surface-European Center of Ceramics (Limoges, France), especially Pascal Marchet and Romain Lucas for their assistance. The financial support of the Natural Sciences 


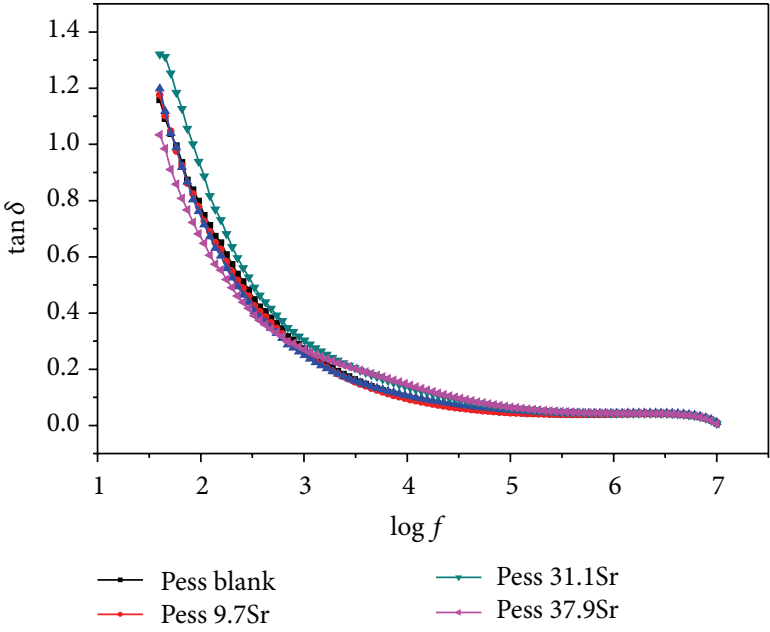

(a)

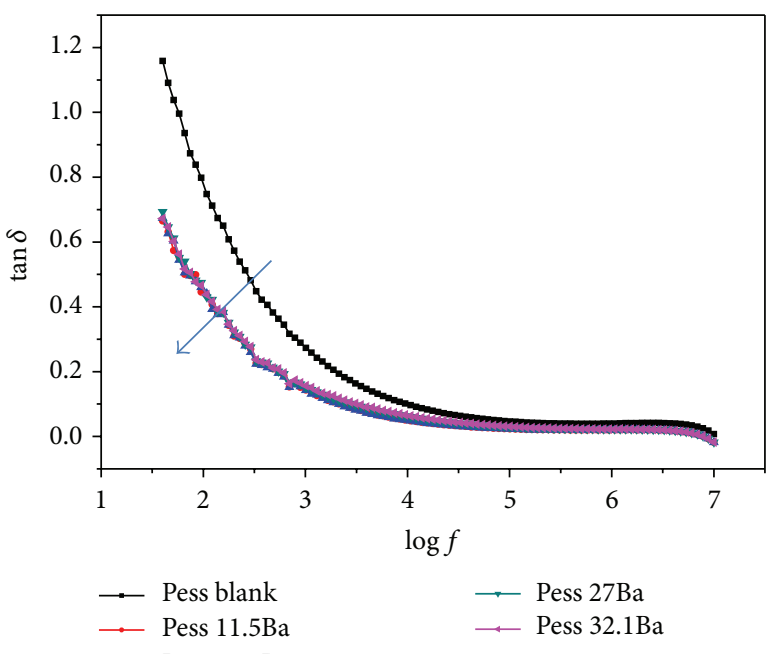

(b)

FIGURE 8: Loss factor for paper loaded by the two ceramics for different percentages.

and Engineering Research Council of Canada (NSERC) is also greatly appreciated. The authors also thank Professor Ahmed Radi, at the Faculty of Letters and Human SciencesMarrakech, who was kind enough to check the translation of this paper.

\section{References}

[1] R. Fournie, Les Isolants en Électrotechnique: Essais, Mécanismes de Degradation, Applications Industrielles, Collection de la DER d'EDF, Eyrolles, Paris, France, 1990.

[2] A. Leminen, A. Johansson, J. Lindholm, J. Gullichen, and Y. Yilmaz, "Non wood fibers in papermaking," VTT Research Notes, pp. 3-9, 1996.

[3] S. P. Katri, "Non-wood plants as raw material for pulp and paper," MTT Agrifood, pp. 12-14, 2001.

[4] M. J. Heathcote and D. P. Franklin, The J \& P Transformer Book: A Practical Technology of the Power Transformer, Newnes, Oxford, UK, 12th edition, 1998.

[5] M. S. Venkatesh and G. S. V. Raghavan, "An overview of microwave processing and dielectric properties of agri-food materials," Biosystems Engineering, vol. 88, no. 1, pp. 1-18, 2004.

[6] H. El-Saied, M. G. El-Meligy, S. H. Mohamed, and S. Abd ElMongy, "Electrical insulated paper from cotton linter," Carbohydrate Polymers, vol. 90, no. 1, pp. 147-151, 2012.

[7] T. Y. A. Fahmy, M. G. El-Meligy, and F. Mobarak, "Introducing deinked old newsprint as a new resource of electrical purposes paper," Carbohydrate Polymers, vol. 74, no. 3, pp. 442-444, 2008.

[8] J. Einfeldt and A. Kwasniewski, "Characterization of different types of cellulose by dielectric spectroscopy," Cellulose, vol. 9, no. 3-4, pp. 225-238, 2002.

[9] N. Saba, P. Md. Tahir, and M. Jawaid, "A review on potentiality of nano filler/natural fiber filled polymer hybrid composites," Polymers, vol. 6, no. 8, pp. 2247-2273, 2014.

[10] A. M. Kaplan, N. I. Chekunaev, L. V. Bezhikina, and V. G. Nikolskii, "Composite papers with enhanced electrical strength," Composites Science and Technology, vol. 51, no. 3, pp. 325-329, 1994.
[11] D. R. Johnston and C. R. Bradley, "Pros and cons of paper and polymeric insulated cables," Power Engineering Journal, vol. 3, no. 4, pp. 215-222, 1989.

[12] R. W. Samm, "How a paper polypropylene-paper laminate insulation will benefit the utility industry," IEEE Electrical Insulation Magazine, vol. 3, no. 4, pp. 41-42, 1987.

[13] R. Liao, C. Lv, L. Yang, Y. Zhang, W. Wu, and C. Tang, "The insulation properties of oil-impregnated insulation paper reinforced with nano-TiO ${ }_{2}$," Journal of Nanomaterials, vol. 2013, Article ID 373959, 7 pages, 2013.

[14] D. H. Shroff and A. W. Stannet, "A review of paper aging in power Transformers," IEE Proceedings C, vol. 132, no. 6, pp. 312319, 1985.

[15] A. M. Emsley and G. C. Stevens, "A review of chemical indicators of degradation of cellulosic electrical paper insulation in oil-filled transformers," IEE Proceedings-Science, Measurement and Technology, vol. 141, no. 5, pp. 324-334, 1994.

[16] I. Fofana, H. Borsi, and E. Gockenbach, "Results on aging of cellulose paper under selective conditions," in Proceedings of the Annual Report Conference on Electrical Insulation and Dielectric Phenomena, pp. 205-208, Kitchener, Canada, October 2001.

[17] F. Mobarak, M. Mounir, F. Mohsen, and A. F. H. Ali, "Studies on the electrical properties of agricultural residues paper I: electrical properties of cotton stalks and wood papers," Cellulose Chemistry and Technology, vol. 33, no. 3-4, pp. 321-331, 1999.

[18] F. Mobarak, M. Mounir, F. Mohsen, and A. F. H. Ali, "Studies on the electrical properties of agricultural residue papers II: electrical properties of rice straw paper and its blends with cotton stalks and wood," Cellulose Chemistry and Technology, vol. 33, no. 5-6, pp. 513-525, 1999.

[19] F. Mohsen and F. Mobarak, "Effect of impregnation with linseed oil on electrical properties of cotton stalks and wood paper," Journal of Scientific and Industrial Research, vol. 55, no. 7, pp. 511-515, 1996.

[20] F. Mobarak, M. Mounir, F. Mohsen, and A. F. H. Ali, "Effect of temperature on electrical properties of cotton stalks and wood paper impregnated by linseed oil," in Proceedings of the International Conference on Chemistry and Technology of Fibers and Textiles, Cairo, Egypt, December 1996. 
[21] L. Segal, J. J. Creely, A. E. Martin, and C. M. Conrad, "An empirical method for estimating the degree of crystallinity of native cellulose using the X-ray diffractometer," Textile Research Journal, vol. 29, no. 10, pp. 786-794, 1959.

[22] Agilent Technologies, Agilent 16451B Dielectric Test FixtureOperation and Service Manual, Agilent Technologies, Hyogo, Japan, 2008, http://www3.nd.edu/ nano/facilities/at_man_Agilent16451B_DielectricTestFixture.pdf.

[23] I. C. Madakadze, T. Radiotis, J. Li, K. Goel, and D. L. Smith, "Kraft pulping characteristics and pulp properties of warm season grasses," Bioresource Technology, vol. 69, no. 1, pp. 75-85, 1999.

[24] I. C. Madakadze, T. M. Masamvu, T. Radiotis, J. Li, and D. L. Smith, "Evaluation of pulp and paper making characteristics of elephant grass (Pennisetum purpureum Schum) and switchgrass (Panicum virgatum L.)," African Journal of Environmental Science and Technology, vol. 4, no. 7, pp. 465-470, 2010.

[25] J. Ai and U. Tschirner, "Fiber length and pulping characteristics of switchgrass, alfalfa stems, hybrid poplar and willow biomasses," Bioresource Technology, vol. 101, no. 1, pp. 215-221, 2010.

[26] S. Belkhir, A. Koubaa, A. Khadhri, M. Ksontini, and S. Smiti, "Variations in the morphological characteristics of Stipa tenacissima fiber: the case of Tunisia," Industrial Crops and Products, vol. 37, no. 1, pp. 200-206, 2012.

[27] J. M. Dinwoodie, "A review of literature on the relationship between fiber morphology and paper properties," Tappi, vol. 48, no. 8, pp. 440-447, 1965.

[28] J. P. Casey, Ed., Pulp and Paper: Chemistry and Chemical Technology, John Wiley \& Sons, New York, NY, USA, 3rd edition, 1980 .

[29] J. Görres, R. Amiri, J. R. Wood, and A. Karnis, "Mechanical pulp fines and sheet structure," Journal of Pulp and Paper Science, vol. 22, no. 12, pp. J491-J496, 1996.

[30] J. Sirviö and I. Nurminen, "Systematic changes in paper properties caused by fines," Pulp and Paper Canada, vol. 105, no. 8, pp. 39-42, 2004.

[31] U. Tschirner, S. Ramaswamy, and A. Goel, "Effect of cereal straw fibre addition to papermaking furnish," Pulp and Paper Canada, vol. 104, no. 10, pp. 26-29, 2003.

[32] E. O. Fernandez and R. A. Young, "An explanation for the deviation from linearity in properties of blends of mechanical and chemical pulps," Tappi Journal, vol. 77, no. 3, pp. 221-223, 1994.

[33] Y. Deyong, "Drainage aids for bleached wheat straw," in Proceedings of the 3rd International Non-Wood Fiber Pulping and Papermaking Conference, pp. 441-450, Beijing, China, October 1996.

[34] R. S. Seth, “The measurement and significance of fines," Pulp and Paper Canada, vol. 104, no. 2, pp. 41-44, 2003.

[35] M. Jacob, K. T. Varughese, and S. Thomas, "Dielectric characteristics of sisal-oil palm hybrid biofibre reinforced natural rubber biocomposites," Journal of Materials Science, vol. 41, no. 17, pp. 5538-5547, 2006.

[36] N. Chand and D. Jain, "Effect of sisal fibre orientation on electrical properties of sisal fibre reinforced epoxy composites," Composites Part A: Applied Science and Manufacturing, vol. 36, no. 5, pp. 594-602, 2005.

[37] G. George, K. Joseph, E. R. Nagarajan, E. Tomlal Jose, and K. C. George, "Dielectric behaviour of PP/jute yarn commingled composites: effect of fibre content, chemical treatments, temperature and moisture," Composites Part A: Applied Science and Manufacturing, vol. 47, no. 1, pp. 12-21, 2013.

[38] A. M. A. Nada, M. Dawy, and A. H. Salama, "Dielectric properties and AC-conductivity of cellulose polyethylene glycol blends," Materials Chemistry and Physics, vol. 84, no. 2-3, pp. 205-215, 2004.

[39] I. Z. Selim, A. H. Basta, O. Y. Mansour, and A. I. Atwa, "Hydroxyethyl cellulose. II. IR spectra and their relation with the dielectric properties of hydroxyethyl celluloses," PolymerPlastics Technology and Engineering, vol. 33, no. 2, pp. 161-174, 1994.

[40] M. G. El-Meligy, S. H. Mohamed, and R. M. Mahani, "Study mechanical, swelling and dielectric properties of prehydrolysed banana fiber-waste polyurethane foam composites," Carbohydrate Polymers, vol. 80, no. 2, pp. 367-373, 2010.

[41] R. Popielarz and C. K. Chiang, "Polymer composites with the dielectric constant comparable to that of barium titanate ceramics," Materials Science and Engineering: B, vol. 139, no. 1, pp. 48-54, 2007.

[42] G. A. Baum, "Electrical properties: I. Theory," in Handbook of Physical Testing of Paper, pp. 333-359, Marcel Dekker, New York, NY, USA, 2nd edition, 2002.

[43] S. Simula, S. Ikäläinen, K. Niskanen, T. Varpula, H. Seppä, and A. Paukku, "Measurement of the dielectric properties of paper," Journal of Imaging Science and Technology, vol. 43, no. 5, pp. 472-477, 1999.

[44] X. Y. Huang, Z. S. Ma, Y. Q. Wang, P. K. Jiang, Y. Yin, and $\mathrm{Z}$. Li, "Polyethylene/aluminum nanocomposites: improvement of dielectric strength by nanoparticle surface modification," Journal of Applied Polymer Science, vol. 113, no. 6, pp. 3577-3584, 2009. 

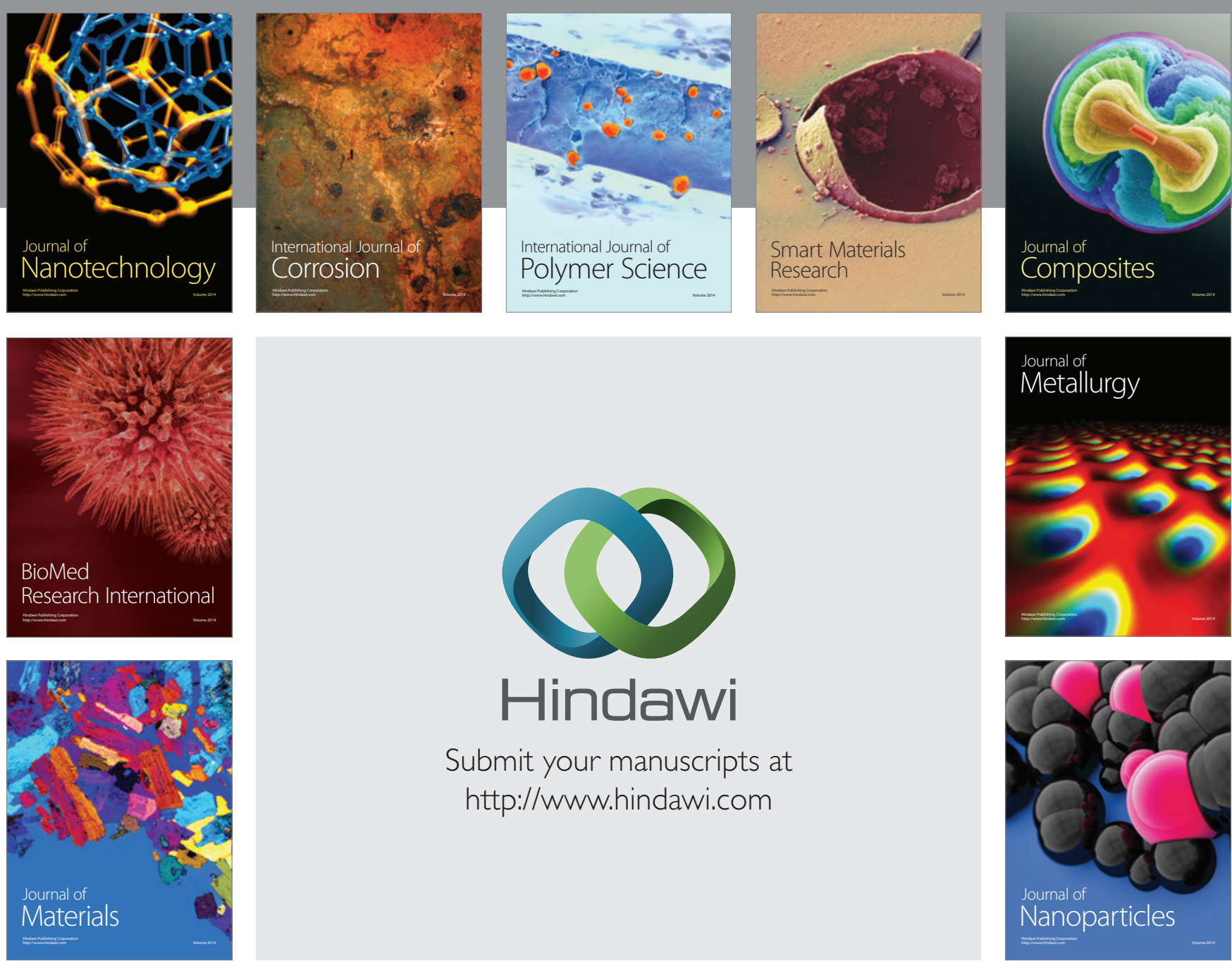

\section{Hindawi}

Submit your manuscripts at

http://www.hindawi.com

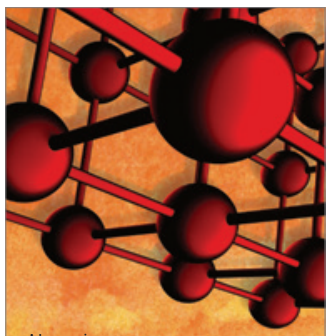

Materials Science and Engineering
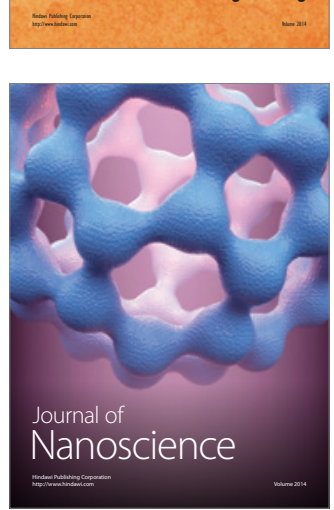
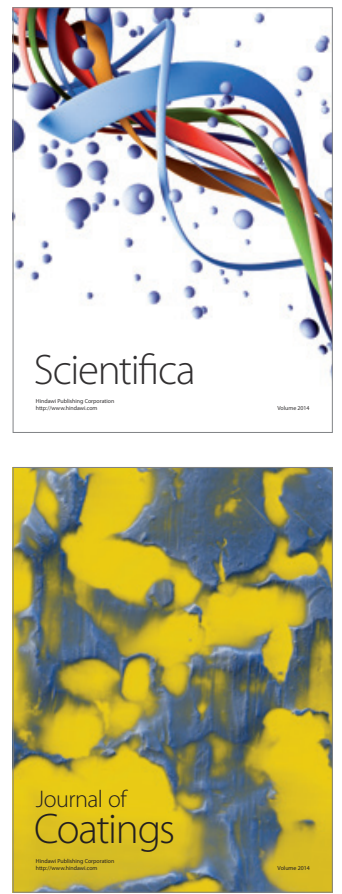
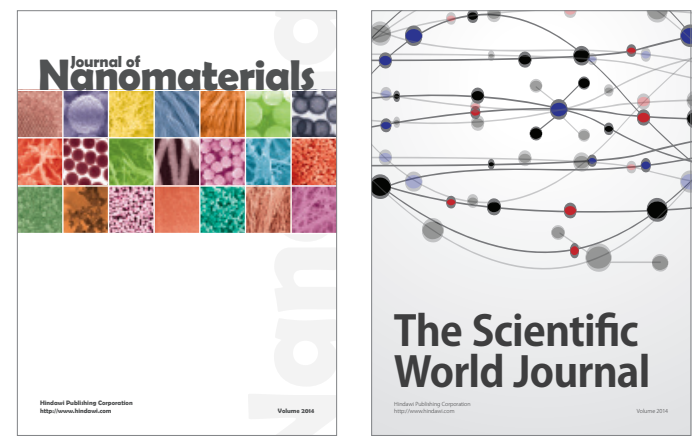

The Scientific World Journal
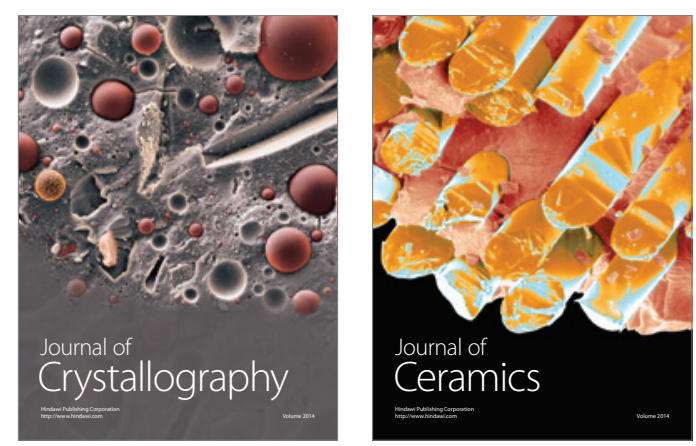
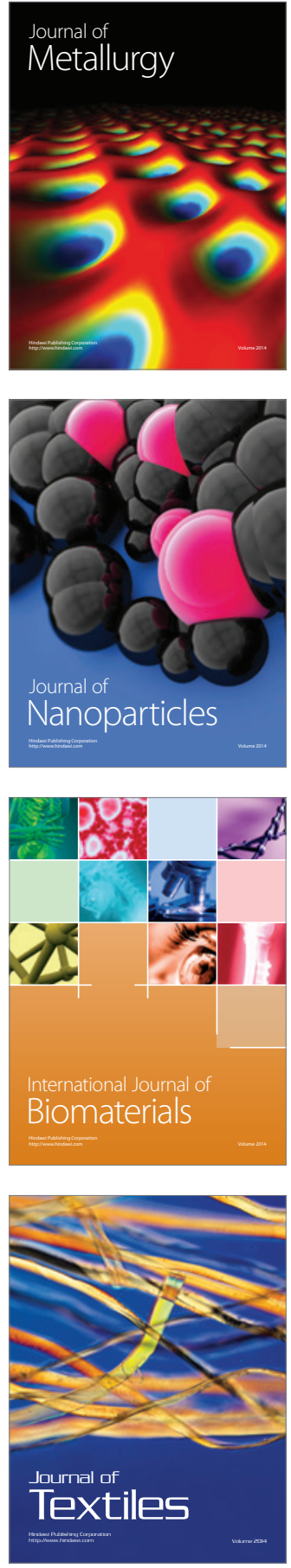